\title{
User perceptions of the quality of nutrition care for children under five year in Botswana
}

\author{
Maria S. Nnyepi ${ }^{1}$, Jenny T. Bond ${ }^{2}$, Brendan Mullan ${ }^{3}$, Mark Uebersax ${ }^{2}$, Lorraine Weatherspoon ${ }^{2}$
}

\begin{abstract}
Background: Perceptions about the quality of healthcare attract a great deal of attention due to their influence on user satisfaction and the continued utilization of health services.

Objective: To examine the perceptions of caregivers and healthcare providers about nutrition care for children aged 0 5 years and the interpersonal communication between providers and caregivers in health facilities in Botswana.

Methods: Ten focus group discussions involving about six caregivers each and survey data from health providers $(\mathrm{n}=$ 39) were used to examine perceptions about nutrition care for children aged $0-5$ years and interpersonal communications between providers and caregivers.

Results: Caregivers examined in this study perceived nutrition and dietary screening and intervention as important components of healthcare for children. However, the caregivers were concerned about the frequent shortage of food supplements, the lack of alternative food supplements and programs for children whose needs were not adequately met by existing services. Poor interpersonal communication between providers and caregivers, shortage of supplements and long queues were also identified as concerns by both caregivers and health providers. Although health care service providers reported to have been trained to provide nutrition and dietary care, many were not satisfied with their present skill level in these areas.
\end{abstract}

Conclusion: The caregivers perceived nutrition care to be an important aspect of care. However, the poor interpersonal communication between providers and caregivers and the low confidence that providers have in their skill level in nutrition care is likely to adversely influence the dependent care abilities of caregivers. [Ethiop.J.Health Dev. 2006;20(3):177-183]

\section{Introduction}

There is a growing interest in the quality of healthcare services that exist in developing countries. In particular, the interplay between users' perceptions of the quality of health care and 'users' satisfaction with and continued utilization of health services has attracted much attention $(1,2)$. It appears that users' perceptions of the quality of health services are influenced by factors related to the competency of providers, access to healthcare, effectiveness of care, availability of health resources and services, and interpersonal relations between users and providers (1, 3-5). Amongst these factors, interpersonal relations between providers and users have emerged as equally important determinants of users' perceptions of the quality of health care as the medical factors. Positive users' perceptions of the interpersonal relations between them and providers have been shown to mitigate the negative impact of the introduction of user fees, lack of equipment and shortage of drugs in developing countries (6). However, the interpersonal relationship between providers and users were neglected during the formative years of many health systems in developing countries (3). Left unattended, the negative user-provider interpersonal relations can lower the utilization of healthcare services (5).

The relative importance of the determinants of users' perceptions across the different health systems may differ due to differences in the characteristics of users and factors unique to the different health systems (7). Therefore, the periodic inclusion of users' perceptions as one of the outcome measures in health systems in evaluation studies is recommended $(8,9)$.

When user perceptions are examined in contexts where the users' use or lack thereof of services affect their dependents care activities, the theory of dependent care can be a logical theoretical guiding principle (10). This theory is a corollary theory to Orem's self-care and selfcare deficit nursing (11). The theory of dependent care links the concepts of dependent care agent, (parent/ caregiver responsibility), dependent care system (activities and networks the dependent care agents have to engage in order to meet the self care requisites of the dependent and the necessary components of meeting the self care demands of the dependent (10). Orem refers to the necessary components as nursing care technologies and these would include human interaction, communication and nursing care or practice (12). In this study, the later would be equivalent to nutrition education, food and nutrition interventions and other aspects of nutrition and health care services that caregivers would receive from meaningful interactions with health providers.

Within the context of this theory, the dependent care 
abilities of users are expected to be influenced by their perceptions of the quality of nutrition care provided in health facilities. Negative user (dependent care agents) perceptions of the quality of nutrition care, we argue, can disinterest caregivers from engaging in meaningful interactions with health providers and thus deny them the opportunity to acquire dependant care abilities from health providers and health services. All this may cause the dependent care agents to develop inadequate dependent care systems for their dependents and thus compromise their care. Because child malnutrition and survival are critical issues of concern in developing countries, and can be compounded by inadequate use of healthcare system or failing healthcare systems, user perceptions of the quality of nutrition care must be such that they encourage continued use of health care services. This is particularly important because the general growth and development of children does not only depend on the social status of their families ard socioeconomic situation of the country but also on the parental knowledge of health and nutrition services and use of primary health care facilities (13).

This study contributes to the body of knowledge on the users' satisfaction with health care services in developing countries by exploring users' satisfaction with nutrition care provided to children aged $0-5$ years in Botswana. An attempt is made to describe caregivers' perceptions of; 1) the importance of nutrition care in the survival of children 0-5 years of age; 2) the adequacy of clinic services in addressing the nutritional needs of children; 3) interpersonal communication between providers and caregivers (users); 4) providers knowledge and perceptions about the adequacy of their training and consequently the nutrition care they provide to children 0-5 years and 5) providers perceptions about their communication with providers. Finally, a theoretical discussion of how the interpersonal communication between providers and caregivers and providers' kniowledge and competence in addressing dietary and the nutritional concerns caregivers have about their children can affect the dependent care abilities of caregivers, is provided within the underpinnings of the dependent care model.

\section{Methods}

Focus group data previously used as a supplementary data source in a study that explored the linkages between Child Survival Programs with matnutrition alleviation strategies in Botswana were examined to characterize the caregivers' perceptions about the quality of nutrition care provided to their children (14). Participants were caregivers whose children had received preventive and/or curative care in randomly selected health facilities in Southern Botswana. The preventive services, which were offered through the Child Welfare Clinic, included growth monitoring, supplementary feeding, and Immunization services while the curative services included primary medical care for various childhood illnesses. The recruitment of focus group participants took place at the clinics after the caregivers exited consultation rooms.

The focus group participants considered; 1) the importance of nutrition assessments and interventions in the clinic care of children $0-5$ years of age, 2) the adequacy of clinic services in addressing the nutritional needs of children, and channels of communication between caregivers and providers in health facilities. The participants were requested to limit their observations to their experiences in their clinics. All focus group discussions were conducted in the respondents' native language (Setswana) and were moderated by the first author.

Overall, ten focus groups of about six members each were conducted. The sessions were captured on videotape. The focus group moderator prepared the transcripts prior to analysis. During the analysis, salient themes specific to each of the research questions were identified and the frequency of their occurrence across the groups was established. Careful attention was taken to establish the frequency of occurrence of themes, phrases and expressions that users (caregivers) used to describe their perceptions relative to the specific research questions.

In addition, a structured questionnaire was used to obtain data from health providers in the study clinics. Data collected included: demographic characteristics, providers' perceptions about the adequacy of their training in dietary and nutrition screening and interventions, established communication channels in their clinics and perceptions about interpersonal communication between providers and caregivers.

\section{Results}

Caregivers' perceptions about nutrition care: Caregivers perceived nutrition and dietary assessment to be important for their children. In all the ten focus groups, the importance of nutrition care in both the curative and preventive programs was mentioned (Box 1). There was a strong sense that the programs should work together to provide nutrition interventions. Expressions such as "the programs should work together", "assist each other", "refer ill children between the clinics" were common across the groups.

As shown in Box 2, caregivers across most groups raised several concerns about the adequacy of nutrition care. These concerns included the perceived inadequacy of nutrition assessment, the irregular supply of supplementary foods, lack of Vitamin A doses, and the lack of special programs for children perceived to be particularly malnourished. Participants also raised concerns about the lack of alternative supplements for 
Box 1: Focus group excerpts ${ }^{1}$ that indicate caregivers' perceptions about the importance of nutrition care for children seeking care from health facilities ${ }^{1}$

III children should get medical care first, then the child's nutritional status should ${ }^{3}$ be assessed $(1,6-7,10)^{2}$

- When children are ill their nutritional status should be evaluated because children tend to lose weight when they are ill (8)

- Nutrition and dietary screening should occur in both the growth monitoring (preventive) and curative clinic (5).

- The clinics should work together (1-10)

- The growth monitoring clinic should refer ill children to the curative clinic (4)

- Clinics should assist each other in addressing nutrition and dietary needs (4)

- If clinics cannot give you the right food for your child they shquild tell you what food to provide for your child (6)

- Since Growth Monitoring attendance occurs once a month for each child, children who lose weight in between visits should not wait the whole month for the next Growth Monitoring Clinic; they should be taken to the curative clinic $(8,10)$

- There should be a special nutrition class for pregnant women. ...all we hear in education classes are immunization schedules (7)

\footnotetext{
${ }^{\top}$ Excepts in this figure and the subsequent figures were translated from Setswana to English by the first author

${ }^{2}$ The numbers in b identify the focus group from which the statements or phrases were extracted.

${ }^{3}$ Phrases or words that reflected caregivers' perception about the provision of nutrition care are underlined
}

ckildren perceived to have a poor tolerance for tsabana (sorghum-soy bean supplementary food). In two groups, participants suggested that a replacement program for the Direct Feeding Program, an intense nutrition rehabilitation program that ceased in the mid 1980s, needs to be put in place (15). Alongside this program, participants also wanted providers to routinely assess the general needs of caregivers whose children are chronically undernourished, as the child's chronic conditions may be suggestive of the caregivers' general needs. Overall, in seven of the ten groups, caregivers' comments suggested that providers can do more to improve the perceived adequacy of nutrition care provided to children.

In three of the groups, some participants indicated that providers often asked a lot of questions in an attempt to screen children who were found to have lost weight during clinic visit. Some of the questions that providers are reported to have asked related to the feeding practices of the caregivers and the illness history of the children.

\section{Box 2: Caregivers' Concerns about the Inadequacy of Nutrition Care (Focus Group Number)}

\section{Resources Not Always Adequate:}

- Irregular supply of food in the supplementary feeding package $(1,8)$

- Vitamin A doses often not available $(8,9,10)$

- Infant scales not available $(6,8)$

- No special program for very malnourished children $(6 ; 8)$

- No alternate food supplements for children who do not tolerate weaning food (2)

- Lack of variety $(1,8)$

Lack of Nutrition and dietary Intervention Activities

- Nutrition and dietary assessment, education or guidance rarely provided $(1,2,8,9,10)$

- No educational flyers about nutrition (6)

- $\quad$ No help for caregivers with children who refuse to eat $(4,9)$

- Providers give conflicting advice for children who refuse to eat (4)

- No help for households with frequently ill or malnourished children (8)

- $\quad$ No special care for children who have lost much weight $(6,10)$

- No expedited care for children perceived to be very ill or very malnourished (long lines; very ill/malnourished children are expected to join long lines like any other clinic client $(1,6)$

Providers' perceptions about nutrition training: About seventy-one percent of the providers included in the study reported that their pre-service training in nutrition adequately prepared them to provide nutrition and dietary care to children. However, a smaller proportion of the providers were comfortable with their present skill level in providing nutrition (57.9\%) and dietary care (53\%) (Table 1). When asked to list three indicators that could reflect the risk of poor nutrition and dietary intake in children, only $12.8 \%$ and $35.9 \%$ were able to correctly list three indicators of nutritional status or dietary intake respectively. The providers gave variable and often conflicting responses to questions requiring them to provide specific examples of indicators they routinely used to screen children. For example, while $82.1 \%$ of the providers reported that they routinely assessed the growth of children, only $45.5 \%$ reported that they routinely measured the weights of the children they consulted on. 


\begin{tabular}{|c|c|c|c|}
\hline Variable & $\mathbf{N}(\%)$ & Variable & $N(\%)$ \\
\hline $\begin{array}{l}\text { Perceived adequacy of training in } \\
\text { assessing dietary intake } \\
\text { Adequate } \\
\text { Somewhat adequate } \\
\text { Not adequate }\end{array}$ & $\begin{array}{c}27(69.2) \\
7(17.0) \\
5(12.9)\end{array}$ & $\begin{array}{l}\text { Perceived adequacy of training in } \\
\text { assessing nutrition risk } \\
\text { Adequate } \\
\text { Somewhat adequate } \\
\text { Not adequate }\end{array}$ & $\begin{array}{c}27(71.1) \\
8(21.1) \\
3(7.9)\end{array}$ \\
\hline $\begin{array}{l}\text { Number of appropriate methods for } \\
\text { assessing dietary intake } \\
\text { None } \\
\text { One } \\
\text { Two } \\
\text { Three } \\
\text { Never assess dietary intake }\end{array}$ & $\begin{array}{l}7(17.9) \\
5(12.8) \\
6(15.4) \\
14(35.9) \\
7(17.9)\end{array}$ & $\begin{array}{l}\text { Number of appropriate methods for } \\
\text { nutrition screening } \\
\text { None } \\
\text { One } \\
\text { Two } \\
\text { Three } \\
\text { Never assess nutritional status }\end{array}$ & $\begin{array}{l}3(7.7) \\
16(41.3) \\
13(33.3) \\
5912.8) \\
2(5.1)\end{array}$ \\
\hline $\begin{array}{l}\text { Satisfaction with skills for assessing } \\
\text { dietary intake } \\
\text { Satisfied } \\
\text { Somewhat satisfied } \\
\text { Not satisfied }\end{array}$ & $\begin{array}{c}20(52.6) \\
11(28.9) \\
7(18.4)\end{array}$ & $\begin{array}{l}\text { Satisfied with skills for assessing nutrition } \\
\text { risk } \\
\text { Satisfied } \\
\text { Somewhat satisfied } \\
\text { Not satisfied }\end{array}$ & $\begin{array}{c}30(57.9) \\
6(15.8) \\
2(5.2)\end{array}$ \\
\hline
\end{tabular}

\section{Caregivers concerns about interpersonal}

communication: In the discussions regarding communication between providers and users, the participants reported three distinct ways of initiating communication with providers. These are: participants can initiate contact with providers by first contacting the lowest ranking clinic officers especially the Family Welfare Educators, by talking to any visibly accessible provider or.by requesting Family Welfare Educators to arrange a meeting for them with the facility manáger (also referred to. as the Sister-in-Charge). The choice of the users' initial communication contact with the providers was influenced by the subject matter of the communication, and the users' comfort level with providers in general. Most participants indicated that they would prefer to initiate their communication with the Family Welfare Educators.

Some of the statements and phrases that caregivers used to describe their interactions with providers are displayed in Box 4. Statements such as "we fear these people" "we are afraid of them", and "they treat us "like children," were common and suggested negative user-provider interactions. Open communication between providers and users appears to be limited because participants indicated that they were afraid to share their concerns with providers lest the providers become angry with them, perceived them to be bad people or reported them to the matron.

Participants reported that users were to spoken harshly for reasons that included: failure to coat the child's Child Welfare Clinic card, arriving late at the clinic or failure to recall the immunization schedule for children. Overall, the participants stated that it took a lot. of courage for caregivers to approach providers. Despite these difficulties, however, users in one group (group 2) stated that they readily forgave providers because they appreciate the fact that the providers work under pressure (Box 3).

Providers' perceptions about their communication with caregivers: Practitioners fell into two groups with respect to their perceptions about communication channels between them and caregivers (Table 2). One group of practitioners $20(51.3 \%)$ thought that there. were established communications systems between caregivers and clinic staff. In the other group, 15(38.5\%) practitioners felt that there were no established communication channels between caregivers and practitioners, while $4(10.3 \%)$ denied any knowledge of the presence or absence of established systems of communication between practitioners and caregivers.

Among the 20 practitioners who affirmed the existence of well-established communication channels between caregivers and practitioners, nine $(45 \%)$ felt that health education sessions that are routinely held in the clinics constitute one type of communication system that is currently in place. These practitioners felt that caregivers are free to communicate their concerns or make care recommendations about any clinic service during the question and comments sessions following the health talk /education ${ }^{1}$. Six $(30 \%)$ practitioners felt that caregivers were free to contact the sisters-in-charge ${ }^{2}$ of the clinic; and that this free access was perceived to be the second communication channel that takes place between caregivers and practitioners.

\footnotetext{
While at some clinics, the primary researcher sat in with the clients as the health talks were given. The topics varied widely Sessions were open to all in attendance, hence everyone could ask questions. Not all clinics offered health talks. Some caregivers were observed asking questions. ${ }^{2}$ Soster-in-charge of clinic is the local terminology for the nurse who is the head of the clinic.
} 
Practitioners' perceptions about caregivers' satisfaction with clinic services: Most practitioners reported that caregivers were satisfied with clinic services (Table 2). Practitioners also reported that caregivers had shared with them their concerns about the clinic services. However, twenty-three $(60.5 \%)$ practitioners reported that caregivers were dissatisfied with the long queues in the clinics. According to the practitioners, other areas of concern that caregivers identified were the frequent shortages of food supplements and practitioners' use of harsh or "unkind" words when communicating with them.

\section{Box 3: Focus Group Excerpts That Characterize Participants Perceptions of Their Interactions with Providers}

\section{Group 2}

- "Our major problem is that we do not have adequate practitioners. Many times one provider works in the injection room, the consultation room and the dispensary..." A practitioner's job is very tiring. Therefore, when practitioners in their tiredness talk to us harshly we forgive them readily. They are people like us and so they make mistakes."

Group 3

- $\quad$ "It is difficult to share ideas with our practitioners. Only few people communicate with providers. Most people do not come for meetings."

- "Many people are not happy with the way things are being run in the clinics, yet you hardly hear people voicing thert" concerns."

- "When we are satisfied with services, we acknowledge and applaud our practitioners... we show gratitude readily, what is difficult for us to do is to voice our concerns."

Group 4

"Practitioners are very unkind. We are afraid of them. We fear these people."

- "They talk to us like they are talking to little children. I do not like to be scolded by another woman for no apparent reason. They don't talk to us with respect."

- "They don't treat people like people. ... One is even afraid to applaud them when they have done a good job. We are all afraid of them."

Group 5

"There is a way to communicate with practitioners. When a caregiver has a sick member of the family at home, she should come to the clinic and tell any of the practitioners. They usually send someone to your home to assess the patient and decide if the clinic vehicle should.come and transport him/her to the hospital."

Group 6

"We do not tell them anything. We are afraid that they will become angry at us. If you raise a concern and indicate to providers your troubles, they will respond with hurtful words. That is why we are so miserable and hardly tell them anything."

- "We never tell them our concerns because we are afraid they will be angry. If you raise a concern about an aspect of care, they become angry with you. If you tell a provider that when you take such and such an action, you are doing us some disservice, she will respond harshly. That is why we never say anything to them."

Group 8

"They start the education late. In addition, they require us to remember the immunizations schedule for children before they can help us. If you do not know the immunization schedule, they do not help you or if they do, it will be after everyone else has been helped."

Group 10

" "It is not easy to talk to providers. I think it is better to use a suggestion box, where we can all deposit our concerns anonymously. We should not raise our concerns face to face as that might cause friction between caregivers who speak up and providers."

" "If you talk to them face to face, they will think that you are a bad person."

- "We have an idea as to which of the providers to talk to and which ones not to talk to. The problem is that often times approachable providers work in different clinic programs than the problematic providers. Hence, even if the approachable providers are informed about caregivers concerns, they can not do anything to improve the situation."

- How can we thank them? The only person I can applaud is (name of provider). She is the only persoh who is interested in community projects. However, we are afraid to applaud the helpful providers like her because the others might not like it."

- "I can applaud providers, but I have never experienced any deed that instilled in me a sense of gratitude. If it happens; I will have no problem telling providers."

Table 2: Perceptions, communication channels and caregivers' satisfaction

\begin{tabular}{lll}
\hline Variables & $N(\%)$ & Variables \\
\hline $\begin{array}{l}\text { Communication system between caregivers } \\
\text { and practitioners established }\end{array}$ & are caregivers satisfied with clinic services \\
Yes & $20(51.3)$ & Yes \\
No & $15(38.5)$ & No \\
Don't know & $4(10.3)$ & \\
Communication channels & & Top 3 Concerns that caregivers told practitioners \\
Talk to Sister-in Charge of clinic & $6(30.6)$ & Long queues in clinics \\
Suggestion Box & $2(10.0)$ & Shortage of supplements \\
Health talks-open forum & $9(45.0)$ & Practitioners use harsh words \\
Talk to any clinic staff & $3(15.0)$ & \\
\hline
\end{tabular}




\section{Discussions}

We explored user's perceptions about the importance and the adequacy of nutrition care provided to children 0-5 years of age, users' awareness of communication channels between users and providers in their health facilities and health providers knowledge of nutrition and dietary care for children, as well as perceptions about the adequacy of their training in the same areas and perceptions about their communication with caregivers. Nutrition and dietary care for children seeking clinic care was perceived to be very important by caregivers, but the actual nutrition care provided was perceived to be inadequate. Some programs, particularly the Growth Monitoring and the Supplementary Feeding Programs, were perceived to be better at providing nutrition care than the medical clinics because of the provision of food supplements. Hence, participants expected the preventive and curative clinics to constantly work together in providing nutrition care to children.

While the provision of food supplements and providers' initiative in probing for possible nutrition or health problems in children exhibiting growth faltering were the two most frequently given examples that users perceived reflected the efforts of providers in addressing the nutrition needs of children, it is unlikely that such measures were adequate and would be sustainable in addressing nutritional problems of children becau'se of communication challenges reported between providers and caregivers. Beyond the provision of supplements, research suggests that successful and sustainable nutrition interventions are those that combine the provision of supplementary foods with nutrition education, community participation, skill acquisition, and establishment of linkages across community, governmental and non-governmental sectors (16-18). These are factors that require consistent and more positive communication between users and providers than users reported in this study. Observations from previous studies suggest that effective nutrition interyentions are characterized, among other factors, by good communication between providers and users, as well as community, governmental and non-governmental organizations $(16,17)$.

Observations from the quantitative data taken from providers lend some credence to concerns raised by the caregivers. Though most providers reported having been trained in nutrition and dietary care for children, fewer providers were comfortable with their present skill level in these areas. Perhaps, of greatest concern to us, was the fact that most providers were not able to list the correct risk indicators of poor nutritional status and dietary intake although most providers reported that- they routinely screened children for poor nutrition and dietary intake.
The interpersonal communication challenges that caregivers face and which are suggested by focus group discussion data to exist in this study were corroborated by providers. Interpersonal communication challenges was the third most common concerns caregivers reported to providers, the first two being the long queues at the health facilities and the shortage of food supplements. Although we can not quantify the agreement between observations made from the providers and the caregivers' data sets, we can definitively conclude that concerns about the long queues, the shortage of food supplements and poor interpersonal communication were salient issues from both data'sets.

The apparent interpersonal challenges between providers and caregivers might be better explained by focusing on caregivers' level of despair as might be implied from caregivers description of communicating with providers as being unnecessary or not useful (would not make a difference), or providers as being difficult to approach, and being too busy. Although definitive explanations about the nature of the communication difficulties between caregivers and providers in this population require further study, other studies have documented similar challenges in client-provider interactions $(3,6$, $19,20)$ These studies document inadequate verbal communication or unsatisfactory interpersonal relations between caregivers and practitioners in primary health care settings in developing countries $(3,6,19,20)$. Razum (20) reported conflicts between caregivers and providers similar to those reported by caregivers in this study. In Razum's study (20), for example, carẹgivers report being spoken to harshly for arriving late at the clinic or for a misplaced healthcare card.

Interpersonal relations between caregivers and providers play a major part in caregivers' perceptions about the quality of primary health care in developing countries (3, 6). In a study conducted in Zaire, for example, caregivers perceived interpersonal qualities such as respect, patience, courtesy, attentiveness and straightforwardness as the best qualities for providers (nurses) and tended to perceive care provided by providers with these qualities as being better care than that provided by providers who were perceived differently $(3,6)$.

The low knowledge level of providers in nutrition screening and care and the poor interpersonal communication between providers and caregivers in this study have serious implications on the ability of providers to support caregivers in the nutrition care of their children. This holds both within the context of the UNICEF Framework of Child Survival and the theory of dependent care. As conceptualized in the UNICEF Framework of Child Survival, caregivers' access to information and services about health care, maternal and 
different labor within the town as and when they get the chance (Table 2).

Of the child laborers that were working individual homes, $12.3 \%$ took care of cattle (herd cattle in the field, cut grass, remove their waste, etc), $23.3 \%$ mentioned that they were taking care of children (carry kids, look after and wash kid's clothes, etc), $23.3 \%$ bake injera and $30.1 \%$ washed family clothes. But the majority $(60.3 \%)$ of the domestic laborers reported that they did all household works as ordered by their employers.

Table 2: The Working Conditions of Child Laborers $(n=323)$

\begin{tabular}{|c|c|c|}
\hline \multirow[t]{2}{*}{ Variables } & \multicolumn{2}{|c|}{ Respondents } \\
\hline & Frequency & Percentage \\
\hline \multicolumn{3}{|c|}{ Reasons for being Child laborer* } \\
\hline Search for work (Poverty) & 196 & $(60.7 \%)$ \\
\hline Parental Loss & 56 & $(17.3 \%)$ \\
\hline Parental Separation & 21 & $(6.5 \%)$ \\
\hline Disagreement with parents & 27 & $(8.4 \%)$ \\
\hline War & 5 & $(5.1 \%)$ \\
\hline Drought (Shortage of food) & 17 & $(5.3 \%)$ \\
\hline Others & 1 & $(0.3 \%)$ \\
\hline \multicolumn{3}{|l|}{ Types of work } \\
\hline Domestic worker & 165 & $(51.1 \%)$ \\
\hline Working on Street & 73 & $(22.6 \%)$ \\
\hline In private organizations & 59 & $(18.3 \%)$ \\
\hline Working any labor works & 26 & $(8.0 \%)$ \\
\hline \multicolumn{3}{|l|}{ Daily working hours } \\
\hline $8-10$ & 111 & $(34.4 \%)$ \\
\hline $11-12$ & 124 & $(38.4 \%)$ \\
\hline More than 12 & 88 & $(27.2 \%)$ \\
\hline \multicolumn{3}{|l|}{ Amount of Daily income } \\
\hline Less than 5 Birr & 249 & $(81.9 \%)$ \\
\hline $5-10$ Birr & 41 & $(13.5 \%)$ \\
\hline 11-15 Birr & 8 & $(2.6 \%)$ \\
\hline More than 15 Birr & 6 & $(2.0 \%)$ \\
\hline \multicolumn{3}{|l|}{ Duration Stayed in the work } \\
\hline Less than one year & 87 & $(26.9 \%)$ \\
\hline $1-2$ years & 73 & $(22.6 \%)$ \\
\hline More than two years & 163 & $(50.5 \%)$ \\
\hline
\end{tabular}

About $73.0 \%$ of the respondents working in private organizations mentioned that they served as waiters providing coffee, tea, or meal service in the hotels, restaurants and bars. Most of these (about three-fourths) were sex workers who serve as waiters without payment. Furthermore, $16.9 \%$ of the respondents working in private organizations provided accommodation services (renting bed rooms) and $10.2 \%$ provided cleaning services (including cleaning bed rooms and bed cloths) in the hotels.

The overwhelming majority $(94.1 \%)$ of the child laborers reported that they got payment for the work they performed. About eighty two percent of the respondents mentioned that their daily income is less than 5 Birr, $13.5 \%$ of them had a daily income of between $5-10 \mathrm{Birr}$ and only $1.7 \%$ earned $16-20$ Birr. However, about $72.4 \%$ of them mentioned that they are not happy with the amount paid for the work.

Concerning average daily working hours, the majority $(65.6 \%)$ of the respondents worked for more than 10 hours per day, while $34.4 \%$ worked for $8-10$ hours. Half $(50.5 \%)$ of the respondents have staved in the job for more than two years.

\section{Reasons for Being Child Laborer and Family} Condition: Concerning the reasons for child labor, $60.7 \%$ of them reported that they came to this place in search of work, $17.3 \%$ due to loss of parents, $8.4 \%$ due to disagreement or quarrel with parents, $6.5 \%$ because of parental separation, $5.3 \%$ due to shortage of food (drought or famine), and only $1.5 \%$ reported they were displaced because of war (Table 2). The result shows that $77(23.8 \%)$ of the child laborers were from btoken families (one or more of their parents were not alive or have separated).

Among the respondents $63.3 \%$ came from rural areas and the rest $(36.8 \%)$ were from urban areas (most of them from Soddo, Arbaminch, and Awassa towns). Furthermore, $185(57.3 \%)$ of the child laborers were from farming families. Other occupations of the respondents' families included small-scale merchants 
$(13.6 \%)$, daily laborers $(10.8 \%)$, employees of private organizations $(7.4 \%)$, civil servants $(3.7 \%)$, pensioned $(3.4 \%)$, and ex-army members $(0.9 \%)$. About three percent of the respondents' families had no jobs at the time of the survey.

Two hundred six $(63.8 \%)$ of the respondents mentioned that their family's average household monthly income was less than 50 Birr. The others $(23.2 \%)$ indicated that their family had an average monthly income ranging from $50-100$ Birr. Only $13.0 \%$ of the respondents mentioned their family income was greater than 100 Birr. Among the respondents 255 or $78.9 \%$ reported that they were from poor families.
Health problems, HIV/AIDS and reproductive health: Eighty four percent of the child laborers reported experiencing one or more previous health problems. In this study, previous health problems are defined as health problems encountered by child laborers. within six months before the study was conducted. Malaria-like illness was the major health problem reported by $90.4 \%$ of the respondents. Other health problems reported included diarrhoeal diseases $(31.0 \%)$, eye problem $(11.4 \%)$, respiratory tract diseases $(11.2 \%)$, and some other minor health problems reported were mental problems, skin diseases and sexually transmitted diseases (STDs) (Table 3).

Table 3: Percentage Distribution of health problems encountered, source of Health Care and Health Education Attended as reported by respondents

\begin{tabular}{|c|c|c|}
\hline \multirow{2}{*}{ Characteristic } & \multicolumn{2}{|c|}{ Respondents } \\
\hline & Frequency & Percent \\
\hline \multicolumn{3}{|l|}{ Faced Health problems $(n=323)$} \\
\hline Yes & 271 & 83.9 \\
\hline No & 52 & 16.1 \\
\hline \multicolumn{3}{|l|}{ Diseases Encountered * $(n=271)$} \\
\hline Malaria-like febrile illness & 245 & 90.4 \\
\hline Mental problem & 19 & 7.0 \\
\hline Respiratory tract diseases & 52 & 19.2 \\
\hline Diarrheal diseases & 84 & 31.0 \\
\hline Sexually transmitted diseases & 3 & 0.9 \\
\hline Skin disease & 16 & 5.9 \\
\hline Eye problems & 31 & 11.4 \\
\hline \multicolumn{3}{|l|}{ Sources of Health Care * $(n=271)$} \\
\hline Government health facilities & 234 & 86.3 \\
\hline Private health facilities & 88 & 32.5 \\
\hline Traditional medicine & 4 & 1.5 \\
\hline Did not go anywhere & 22 & 8.1 \\
\hline Others & 3 & 1.1 \\
\hline \multicolumn{3}{|l|}{ Attended Health Education $(n=323)$} \\
\hline Yes & 80 & 24.8 \\
\hline No & 243 & 75.2 \\
\hline \multicolumn{3}{|l|}{ Topic_of Health Education* $(n=80)$} \\
\hline Personal hygiene & 78 & 97.5 \\
\hline Sexually transmitted Diseases & 54 & 67.5 \\
\hline Family planning & 23 & 28.8 \\
\hline Communicable diseases & 57 & 71.3 \\
\hline
\end{tabular}

* More than one kind of disease and source of health care is possible, therefore, percentages may be more than a hundred percent

According to the respondents, malaria-like illnesses had signs and symptoms such as headache, fever, sweating and shivering. The respiratory tract illnesses are characterized by chest pain, cough, fever and purulent sputum.

Among child laborers who reported health problems, $86.3 \%$ attended government health facilities (hospitals and health centers), $32.5 \%$ attended private health institutions and $1.5 \%$ used traditional medicine. Furthermore, $8.1 \%$ of those who reported health problems did not seek any medical treatment (Table 3 ).
Eighty six percent of child laborers wash their body and cloths weekly, $7.1 \%$ once per two weeks and $1.2 \%$ of them once within a month. Observation of clothing, shoe wearing, personal hygiene, etc revealed that street laborers had dirty, old and torn clothing; and most of them were without shoes; and domestic laborers had rough and tough palms.

Among the total respondents only $18.6 \%$ reported to have ever experienced sexual intercourse. A large majority $(88.5 \%)$ of the respondents believe that sexually 
transmitted diseases including HIV/AIDS are the major consequence of sexual intercourse before marriage. Other reported consequences included unwanted pregnancy $(67.8 \%)$, maternal and child mortality $(41.5 \%)$, population growth $(36.8 \%)$ and other health problems $(56.7 \%)$ (Table 4$)$.

Seventy seven percent of the child laborers had heard about sexually transmitted diseases (STDs). Moreover, a large majority $(96.0 \%)$ of them had heard about HIV/AIDS (Table 4). All the FGD discussants had heard about HIV/A.IDS.

Among respondents who had heard about HIV/AIDS, the majority $(92.6 \%)$ got the information from the radio followed by community chatting $(89.7 \%)$, television $(66.5 \%)$, school $(29.7 \%)$, newspapers $(16.8 \%)$, social gatherings $(6.1 \%)$, health institutions $(9.0 \%)$, and organization working for the welfare children $(4.5 \%)$ (Table 4).

Out of those who had heard of HIV/AIDS, the majority $(95.8 \%)$ of the respondents knew the ways of transmission of HIV and were able to specify one or more of the common ways of transmission of the disease. Of those who reportedly knew the transmission ways, a large proportion (95.5) mentioned that HIV could be transmitted by sexual intercourse. Contaminated utensils were mentioned by $59.0 \%$ of the respondents followed by blood transfusion $\left(55.8^{\circ} \%\right)$ and mother to child transmission $(40.3 \%$ ) (Table 5).

About $96.0 \%$ of the respondents believed that HIV/AIDS is not a curable disease but that it could be prevented. The prevention methods mentioned include using condoms $(90.6 \%)$, abstinence from sexual intercourse $(93.2 \%)$, having a single sexual partner $(32.6 \%)$ and avoiding multiple sex partner (stop sexual promiscuity) $.58 .7 \%)$ (Table 5).

About three-fourths (75.2\%) of the total respondents did not attend any kind of health education programs. Only a quarter of them attended one or more kinds of programs. Of those respondents who attended health education programs, $97.3 \%$ participated in personal hygiene and sanitation programs, $67.5 \%$ on STD and HIV/AIDS activities, $71.3 \%$ on communicable diseases, and $28.8 \%$ on family planning and unwanted pregnancy related activities (Table 3 ).

Knowledge of child right convention (CRC): A majority of the child laborers ( 250 or $77.4 \%$ ) had never heard of $\mathrm{CRC}$ and were not aware of children's rights. Only $22.6 \%$ of them reported that they knew one or more of the components of CRC. All key informants (KIs) who participated in the study had knowledge on CRC and the KIs reported that the wider community was not aware of the existence of CRC.

Table 4: Percentage distribution of respondents of sexual practice, knowledge about consequence of sex before marriage and sources of information about HIVIAIDS ( $n=323$ ) Characteristic Respondents

Frequency Percent

\begin{tabular}{lcc}
\hline Ever Had Sexual intercourse & & \\
Yes & 60 & 18.6 \\
No & 263 & 81.4 \\
Consequence of Sex before Marriage & & \\
Unwanted pregnancy & 219 & 67.8 \\
Sexually transmitted Diseases (STDs) & 286 & 88.5 \\
Child and mother Mortality (death) & 134 & 41.5 \\
Health problem & 183 & 56.7 \\
Population growth & 119 & 36.8 \\
Others & 8 & 2.5 \\
Heard about HIVIAIDS & & \\
Yes & 310 & 96.0 \\
No & 13 & 4.0 \\
Source of Information about HIVIAIDS & & \\
Radio & 287 & 92.6 \\
Television & 206 & 66.5 \\
School & 92 & 29.7 \\
Health Institution & 28 & 9.0 \\
Organization working toward children & 14 & 4.5 \\
Social gathering & 19 & 6.1 \\
News paper & 52 & 16.8 \\
Community chatting & 278 & 89.7 \\
Others & 5 & 1.6
\end{tabular}

*more than one response is possible; therefore, percentages may be more than a hundred percent 
'Table 5: Percentage distribution of respondents by knowledge of way of transmission, and methods of prevention of HIVIAIDS ( $n=323)$

\begin{tabular}{lcc}
\multicolumn{1}{c}{ Characteristic } & \multicolumn{2}{c}{ Respondents } \\
\cline { 2 - 3 } & Frequency & Percent \\
\hline Ways of HIV Transmission & 297 & 95.8 \\
Sexual intercourse & 173 & 55.8 \\
Blood transfusion & 125 & 40.3 \\
Mother to child & 183 & 59.0 \\
Contaminate utensils & 4 & 1.3 \\
Others & & \\
HIVIAIDS can be prevented & 310 & 96.0 \\
Yes & 13 & 4.0 \\
No & & \\
Methods of HIVIAlDS prevention & 213 & 32.6 \\
Sex with single partner & 281 & 90.6 \\
Use condom & 289 & 93.2 \\
Abstinence & 182 & 58.7 \\
Stop promiscuity & 1 & 0.3 \\
Other & & 3.7 \\
HIVIAIDS can be cured & 12 & 96.3 \\
Yes & 311 & \\
No & & \\
\hline
\end{tabular}

* More than one response is possible; therefore, percentages may be more than a hundred percent.

On the other hand, those child laborers who had heard about child rights were asked about the main component of the CRC. The article "children should have primary consideration in all aspects" was mentioned by $86.3 \%$. The article "children have the right to be educated" was mentioned by $87.7 \%$ of the respondents. Furthermore, $78.1 \%$ of them reported that "children should not be discriminated in many ways", $34.2 \%$ of the respondents mentioned that "the child shall be registered immediately after birth and shall have the right from birth to a name, and the right to acquire a nationality" and $28.8 \%$ of the respondents knew "freedom of association and peaceful assembly".

Among the child laborers who knew about CRC, $94.5 \%$ got the information from radio followed by television $(72.6 \%)$, newspapers $(43.8 \%)$, public gatherings and health institutions $(8.2 \%)$, organizations working towards childrens' issues $(19.2 \%)$ and policeman / justice workers $(8.2 \%)$. The rest $(13.7 \%)$ reported that they heard about it from other different sources.

Results from the FGD indicated that the child laborers had the following major problems:

- Because they are helpless some individuals pay less amount of money or not at all for the work they performed. The existence of such problem was confirmed by the results of observation.

- Because of their living conditions, they are exposed to physical abuse, (they were beaten by their employers; beaten and robbed frequently by older street boys). Results of observation made at their working places and a case study in the police station have confirmed the existence of such problems.
- Due to heavy work lood, poor working conditions, malnutrition, exposure to harsh environmental conditions (working during very cold and hot weathers) and poor sanitation they become vulnerable to diseases

- Because of long hours of work, denial of permission from their employers and financial problem for payment of tuition fee, they are not able to get the opportunity for education.

\section{Discussion}

Consistent with the ILO Minimum Age Convention of 1973, article No. 138 (14), the Labor Proclamation of Ethiopia no. $42 / 1993$ Article 89 has established a minimum age for employment at 14 years and stipulates that children below 14 years are not allowed to work (15). Despite the presence of the proclamation, the present study revealed that many children (about $42.2 \%$ of the respondents) between the ages of 5 and 14 engaged in hard labor for various socio-economic reasons.

Even though the majority (72.4\%) of the children in the study area have attended primary school, none of them were at school during the study. This is worse than the educational condition reported by ILO (9). According to the results of the FGD, the major reasons mentioned for not attending school are "not being able to afford to pay for tuition, absence of time (working for long periods of time), being too tired to go to school in the evening and a few of them mentioned lack of permission from employers". According to Kifle (16), the children's right to develop fully is not adequately protected unless the child is educated. Therefore, the study shows that child laborers are not privileged with education and this is in violation of CRC. 
The fact that the majority $(63.3 \%)$ of the respondents came from rural areas and $57.3 \%$ belonged to farmer families is an indication of the migration of child laborers from rural areas. According to ILO (1), rural-to-urban migration is the cause of the increasing rate of child labor in the urban area of developing countries. And therefore, rural - urban migration is one of the factors that forces children in to child laborers. These children are at risk of being child laborers, exposure to street life, and prostitution.

Results from both quantitative (cross-sectional survey) and qualitative studies (KI interview and FGD) revealed that conditions such as parental death; conflicts (disagreement) with their parents, divorce and separation of parents, lack of parental assistant, being school dropouts, and search for job are considered to be factors that might have contributed to rural- urban migration and consequently to being child laborers. These reasons agree with those reported by Teferra, et.al., (9).

The results show that $56.3 \%$ of the child laborers were from broken families (one or more of their parents are not alive) and $6.2 \%$ of them mentioned parental separation as one of the reasons for being laborers. According to the information from KIs, those children reared or handled normally by their parents are mostly productive. On the contrary, when parents are unable to fulfill the interests of their children, the conditions may lead to migration of children to other areas to fulfill their needs.

The occupation and the amount of income of family is expected to have an impact in shaping the personality of children. As indicated above, more than half of the respondent's families were farmers $(57.3 \%)$ and about three percent of the respondents' families had no jobs at the time of the survey. About $64.0 \%$ of the respondents' families had a monthly income of less than 50 birr and $79.0 \%$ of the laborers reported that they were from poor families. Moreover, about $61.0 \%$ of the respondents indicated that they came to the study towns in search of work due to poverty.

UNICEF (2001) emphasizes that among the underlying causes of child labor, poverty and economic disparity to be critical factors. For example, it is reported that poverty, worsening economic conditions and a decline in the provision of social services have forced large numbers of children in Tanzania to work, as domestic laborers, as street vendors, in mines, on farms and plantations and in prostitution. These results indicate that poverty was the major reason for being laborers.

The household size (the number of children in the family) may be used to estimate the degree of family crowdedness, and economic status and has great implication on the poverty and health status of the family. According to CSA (2), an average household size for an urban family is 4.1 . The results of the present study revealed that three-fourths of the respondent's families had greater than four children at the time of the study indicating large family size.

In general, the study clearly showed that factors such as migration from rural-to-urban areas; family breakdown; large family size; the occupation, amount of income and economic status of family; and most importantly, povetty, are the major factors that expose children to vulnerable situations like child labor.

In Ethiopia, as elsewhere in developing countries, children are the most vulnerable to and often hardest hit by poverty. Poverty affects the ability of society at all levels to fulfill the nededs of children. The effects of poverty are life-long causing both physical and mental damage to the children, more likely passing on poverty to their own children, thereby maintaining the poverty cycle.

Information on the number of hours spent on work has great importance to understand the extent of child labor. A majority of the respondents were engaged in full-time work. Two-thirds of them were working longer than ten hours a day. Moreover, the results of the FGD indicated that they were forced to work on weekends and holidays. A large proportion $(60.3 \%)$ of the domestic workers did all types of household works without discrimination: A 15 year old FGD discussant mentioned that "as I finish one type of work I have to continue another one and so on until all is complete".

Even though the majority $(94.1 \%)$ of the child laborers reported that they are paid for their work, a large proportion $(72.4 \%)$ of them were not happy with the amount of money paid. This seems to be because about $82.0 \%$ of them get a daily income of less than 5 Birr. This is less than the amount paid for adult daily laborers.

About half of the child laborers stayed in the job for more than two years. As reported by most of the FGD participants, most of them did not visit their parents or relatives for long periods of time. The reasons mentioned for this are because there is no known time of vacation and their employers were not willing to give them permission.

According to Ziglar and Hall (17), for a child to develop in a healthy and normal way, it is necessary to meet not only the basic needs of protection, food and health, but also the basic need of affection, interaction and stimulation, and learning through exploration and discovery. As mentioned by Myers (18), therefore, the loss of affection and long term separation of child laborers from the family environment observed in the 
present study are not healthy for children's social development.

The Labor Proclamation of Ethiopia No. 42/1993 subjects employment of young workers between 14 and 18 years to certain conditions such as maximum of seven working hours per day, prohibition of overtime work, night work and provision of weekly rest and public holidays (15). Despite all these, the present study revealed that chiid laborers are exposed to conditions that violate the proclamation. That is, the child laborers are exploited by working restlessly for long hours and performing the jobs for a very low amount of payment. They have no time for education, no means of recreation and leisure, and are unable to visit their families or relatives, as they are working longer hours including weekends and holidays.

Street child laborers seem to be exposed to child abuse and exploitation more often than other types of laborers. They are often times denied payments or forced to take less payment than agreed; abused or exploited by older street laborers; etc. This is supported by results of observation at their work places and FGDs. Most of the younger child laborers mentioned that "In the areas where there is good business we have to pay the older street laborers a small amount of money, otherwise they chase us away from the area. The older ones often kick us and order us to work and give the money to them." This clearly shows that in addition to their employers, child laborers are abused and exploited by other people.

Malaria-like illness was reported to be the major health problem of child laborers in the study areas. This seems to be due to the fact that malaria is endemic in the study areas, particularly in. Awassa and Arbaminch. Government health care facilities seem to be the primary choice of health service for child laborers. The reason for this may be that the government health care service charge is cheaper than the private ones. Those who reported using private health care facilities might have used them during emergency situations or used only pharmacies for buying medicines, as they are not expected to afford private clinics, which are expensive. The fact that traditional medicine was used for treatment may be an indication that they prefer treatments that are less costly because of financial problems. Moreover, financial problems, denial of permission to go to health facilities, and lack of willingness on the side of employers to take the sick to health care providers seem to be some of the reasons for not seeking any form of medical treatment.

Observation of clothing, shoe wearing, personal hygiene, etc., revealed that the condition of domestic laborers and child laborers working in private organizations was better than that of the street laborers. This may be because of the presence of washing facilities in their employers' houses and relatively better income. The rough and tough palms of domestic laborers are assumed to be due to constant work for long periods of time. Although the body and clothing washing habit of the majority of respondents seems to be generally good, there were respondents who washed their body and clothes only once per three weeks or for a month. Shortage of time and lack of washing facilities (particularly in the case of street laborers) seem to be the reasons for not washing frequently. However, it is believed that the major factor for poor personal hygiene seems to be lack of knowledge about the effect of personal hygiene and sanitation on their health. Therefore, providing health education aimed at personal hygiene is recommended.

Although the majority (77.4\%) of child laborers reportedly heard of STDs and HIV/AIDS, knowledge of some of them about transmission ways and prevention methods is limited. The fact that some of them are sexually active and had limited knowledge may put them at risk of getting HIV/AIDS. The results show that radio and community chatting are the major source of information about the knowledge of HIV/AIDS. In another way the involvement of organizations working for children in making the children knowledgeable about HIV/AIDS is very poor. Therefore, appropriate information dissemination methods should be selected and used.

The result shows that the majority of child laborers had no idea about CRC. Even those who reportedly knew about CRC had limited knowledge of the major articles (components) of CRC. The results show that the mass media, particularly radio and television, play an important role in providing information about child rights in the study areas. On the other hand, the role of policemen and justice workers in the creation of awareness on CRC is very weak and information dissemination through public gatherings and health institutions was very poor.

Most child laborers, particularly street laborers, blame policemen for not protecting them. They complain that some policemen harass and punish them without any wrong doing. This is supported by the result of the FGD and they mentioned, "sometimes we are nabbed by police for crimes we have not committed. Most policemen do not understand our problem and are not seen protecting children from abuse, and exploitation of older individuals who mercilessly harass and kick us for no reason".

In conclusion, the present study indicated that child laborers could not get the benefit of education as most of the participants are out of school; their health, growth and development are threatened; they have lost the love and affection, care and protection of family because they do not visit their families; and cannot enjoy rest and recreation because they work on weekends and holidays. 
Moreover, their problem is not well understood and not protected by the community and the police. Therefore, intervention areas that should be' stressed are providing free and appropriate education; improving access to existing health care facilities; providing family planning service to parents; providing appropriate health education; heightening the children rights awareness of parents, children and the public; and most importantly, providing family support to alleviate poverty.

It is known that the UN CRC, which Ethiopia has ratified, gives a set of universally accepted standards for the wellbeing of children and provides a legal framework that could be used for the protection, survival and development of children (19). However, many of the working and living conditions observed in the study areas violates the basic provisions of the CRC. As described by UNICEF (20), therefore, child labor could be seen in its broadest and most damaging sense as a human rights violation ón many'different levels.

In the last couple of years the government of Ethiopia has been formally committed to protecting the rights and well-being of its children. Despite various proclamations and efforts related to the wellbeing of children, the impact of efforts made by state agencies charged with responsibility for serving and defending the rights of children seems to be very low. Therefore, in addition to the recommendations mentioned above, strong enforcement of legislation and laws related to child rights are also recommended.

\section{Acknowledgments}

The study was financially supported by the United Nations Children Fund (UNICEF) and we would like to acknowledge UNICEF country office in Ethiopia. We also gratefully acknowledge SNNPRG Labor and Social Affairs Bureau for providing the fund and other cooperation. We would like to thank Ms Theydon, an IFISH volunteer at Awassa College of Teacher Education, for editing the paper.

\section{References,}

1. International Labor Organization (ILO). World Labor Report. ILO, Geneva, Switzerland, 2002.

2. Federal Democratic Republic of Ethiopia, Central Statistical Authority (CSA). Ethiopia Child Labor Survey report. Statistical Bulletin 2001;262.

3. Bonnie TZ, Kennet B.W, Howard E.F. Emotional and behavioral problems and severe academic delays among sheltered homeless children in Los Angeles county. AM.J Public Health 1994; 84: 260-263.
4. Al Persteing G, Rappapaort C and Flanigan J.M. Health problems of homeless children in New York City, Am.J. Public Health 1988;78:1232-1233.

5. Janet W, Edna $M$. The depression of homeless children: A focus of nursing intervention, Comprehensive Pediatric Nursing 1984;14:17-19.

6. Brickner PW, Scanal BC, Cananaru B, etal: Homeless persons and health care. Ann Intern Med. 1986;104:405-409.

7. Transitional Government of Ethiopia, Proclamation No.1/1995, Article 36, 1995; Addis Ababa, Ethiopia.

8. International Labor Organization, Eastern Africa Multidisciplinary Advisory team (ILO/EAMAT). Report of the national workshop on child labor in Ethiopia. 1995; Nazareth.

9. Teferra T, Shiferaw, Shibeshi A. A study on child labor in the informal sector of three selected urban areas in Ethiopia. ANNPCAN, Red Barnet and Danida, 1997; Addis Ababa (unpublished).

10. Seyom G. A study of child labor in the city of Dessie. Amhara Region, 2000 (unpublished).

11. Fekadu D, Alem A. Child labor and emotional disorders in an urban district, Ethiopia: A rapid assessment on Community perception of child labor. Ethiop I Hlth Dev. 2001;15(3):197-202.

12. International Labor Organization (ILO). Convention on the worst form of child Labor of 1999 (No. 182). Geneva: ILO, 1999.

13. Statistical Package for Social Science (SPSS). SPSS for windows, Standard Version. Release 11.0.0, SPSS inc., 2001.

14. International Labor Organization (ILO). Minimum Age Convention of 1973 (No. 138). ILO, Geneva Switzerland, 1973.

15. Transitional Government of Ethiopia Proclamation No. 42/1993, Article 89, 1993; Addis Ababa, Ethiopia.

16. Kifle, A. Child demostic workers in Addis Ababa, Ethiopia. ILO International Programme on the Elimination of Child Labor (IPEC). ILO, Geneva Switzerland, 2000.

17. Zigler EF, Hall MW. Child development and Social policy. 2000; McGraw Hill.

18. Myers C.S. Urban children in distress: Global predicaments and innovative strategies. 1994; Longghorn: Gorden and beach publ.

19. Transitional Government of Ethiopia Proclamation No. 10/1991. 1991; Addis Ababa. United Nations Children Fund. Beyound Child labor, Affirming rights. UNICEF, 2001, 1-16. 